\title{
MATERNIDAD, ABORTO Y CIUDADANÍA FEMENINA EN LA ANTIGÜEDAD
}

\author{
Maternity, abortion and feminine cityzenship in Antiquity \\ Patricia GONZÁLEZ GuTIÉRREZ \\ Universidad Complutense de Madrid \\ E-mail: patriciagonzalezgutierrez@gmail.com
}

Fecha de recepción: 6-III-2011

Fecha de aceptación: 29-III-2011

ReSUMEN: Últimamente la investigación ha prestado un gran interés a la historia de género, siendo un tema ampliamente tratado el del control demográfico, pero se ha centrado más en la existencia y efectividad de los métodos usados que en el significado que esconde. Al analizar el tema del aborto y la anticoncepción en el mundo antiguo, en sociedades donde se acepta tranquilamente el infanticidio, analizaremos la relación de la maternidad con la ciudadanía femenina, así como la importancia dada a la reproducción, tanto la meramente física como la de todo el orden social que conlleva. Para ello se hace necesario analizar no solo las obras médicas o legales que hacen referencia al aborto, sino toda una serie de textos vinculados a la construcción de lo femenino en la Antigüedad. La ambigua relación entre maternidad, aborto e infanticidio nos ayuda a comprender mejor a la mujer antigua, pero también su sociedad e incluso la nuestra.

Palabras clave: Género, aborto, anticoncepción, mujer.

ABSTRACT: Recently, investigations have been focused with great interest in the history of genre, with special attention on demographic control. However, it is the existence and the effectiveness of these control methods what is being analyzed, rather than their hidden meaning. In a general approach to the abortion and contraception in the ancient world, when infanticide was not rare, it will be examined the relationship between maternity and female citizenship, as well as the importance of reproduction either as the physical act itself or as an instrument to fully manage the society. In order to do so it is necessary to study, not only legal or medical books dealing with abortion, but also a whole series of documents linked to the construction of the concept of female in Antiquity. The ambiguous relationship between maternity, abortion and infanticide helps us understand women in that period, their society and eventually even ours.

Key words: Gender, abortion, contraception, women. 
Al estudiar la maternidad, ya no solo en la Antigüedad sino en cualquier época, hay que considerar todas sus dimensiones, ya que no es tan solo un acto de reproducción biológica, sino que implica todo un universo social y cultural para crear un nuevo individuo útil y adaptado a su propia sociedad. Ese proceso tan biológico como cultural puede resultar interrumpido en muchos de sus puntos por diversas razones, ya sean buscadas o no. Desde la infertilidad o el celibato hasta el infanticidio (directo o indirecto) pasando por la anticoncepción o el aborto y hay que tener en cuenta que cada uno de estos asuntos tendrá una consideración diferente, dependiendo de quién, cómo y cuándo suceda. El deseo de controlar o potenciar el número de hijos que tiene un núcleo familiar tanto por parte de la misma familia como por parte del Estado no es algo nuevo, como se ha pensado a veces, sino una constante desde la Antigüedad y aún antes. Pero al estudiar las fuentes sobre el tema en la antigua Grecia y Roma nos encontramos una (muy) aparente inversión de la valoración de los métodos de control demográfico respecto a la moral actual, y eso nos lleva a preguntarnos por qué sociedades que aceptan e incluso alientan en ciertos casos el infanticidio, condenan sin embargo severamente la anticoncepción o el aborto.

La respuesta a esta (de nuevo aparente) contradicción la encontramos al analizar tanto las fuentes directas e indirectas sobre el tema como los textos y evidencias que nos permiten ver de qué forma se articulan en estas sociedades la ciudadanía y el género.

$\mathrm{Al}$ analizar los textos médicos nos encontramos que, pese a la fuerte condena al aborto en la legislación y los discursos morales, los tratados nos hablan de fórmulas anticonceptivas y abortivas sin ningún tipo de reparo ni eufemismos, y hemos de esperar hasta épocas muy tardías para que empiecen a disimularse los abortivos tempranos dentro de los emenagogos. Además se distinguen ambos perfectamente, y si se critican los métodos abortivos más agresivos es por el terrible peligro que corre la madre y no por el hecho mismo del aborto.

Así se citan como métodos "mecánicos" para el aborto el hacer ejercicio agotador, levantar pesos, montar en carro o masajes fuertes en el vientre ${ }^{1}$, es decir, las recomendaciones contrarias a las que se dan para llevar a término un buen embarazo. Los métodos quirúrgicos, llevados a cabo con una larga aguja de metal son los más peligrosos, por el riesgo de perforar el útero u otros órganos de la madre, pero aún así han sido muy usados en la historia, llegando hasta hoy el conocido "método de la percha".

Así mismo se citan numerosos remedios vegetales para el aborto, algunos ineficaces, pero la mayoría de eficacia comprobada, como pueden

1 Gourevitch, Danielle Le mal d'être femme. La femme et la medecine a Rome. París 1984 pp. 206 y ss. 
ser la ruda (ruta graveolens), citada por ejemplo por Dioscórides ${ }^{2}$ o la sabina (juniperus sabina), citada por Catón o Plinio ${ }^{3}$, que provocan contracciones musculares que permiten la expulsión del feto, aunque pueden causar graves hemorragias internas o desgarrar el útero si la dosis no es la adecuada. Así mismo se conoce la acción del azafrán tanto como un emenagogo, como una ayuda al parto en cantidades algo mayores, pero también como abortivo, y es usado aún hoy para tales usos en el Magreb ${ }^{4}$, aunque el precio y la dificultad de conseguir las cantidades adecuadas son un obstáculo. Otras plantas son de difícil identificación, como el silphio o la opopanax, aunque se ha propuesto que sean tipos de cañaheja (ferula communis), cuya efectividad se demostró en experimentos en $1963^{5}$.

Los anticonceptivos también son muy citados, y pueden encontrarse diversas recetas con miel, resinas... para mojar en pesarios que se introducían en la vagina ${ }^{6}$, y cuya efectividad viene más de cambiar el PH vaginal que del efecto taponador que pudieran tener. También se encuentran recetas para consumir oralmente, desde las muy sencillas hasta complicadas recetas con numerosos ingredientes. Por ejemplo la granada (punica granatum) es muy citada como anticonceptiva o abortiva temprana no solo por la literatura médica griega o romana sino también por la india y algunos estudios actuales parecen confirmar esa capacidad.

Los métodos anticonceptivos como el coitus interruptus brillan por su ausencia, ya que supondrían una merma en el placer del hombre, lo cual no estaba ni mínimamente contemplado, pero sí se cita el coito anal o el lavado vaginal, este último de nula eficacia pero que aún así ha perdurado en el tiempo hasta la actualidad ${ }^{8}$.

2 Font Quer, Pío. Plantas medicinales. El Dioscórides renovado. Barcelona 1961. pp. 427.

3 Artuz, Manuel Antonio y Restrepo, Humberto "El aborto inducido. Una visión histórica de su manejo." Colombia Médica 33, 2002, pp. 65-71.

4 Font Quer, Pío. Plantas medicinales. El Dioscórides renovado. Barcelona 1961. pp. 913

5 Riddle, J.M. "Oral Contraceptives and Early terms abortifacients during classical antiquity and the Middle Age". En Past and Present n 132 (1991)

6 Blázquez, José $\mathrm{M}^{\mathrm{a}}$ "Los anticonceptivos en la Antigüedad Clásica” en Alfaro Giner, Carmen y Tirado Pascual, Marta (eds.) Actas del segundo seminario de Estudios sobre la Mujer en la Antigüedad (1998). Valencia 2000. pp. 135 y ss.

7 Riddle, J. M. Contraception and Abortion form de Ancient World to the Renaissance, Cambridge 1992. Pág. 25.

8 Gourevitch, Danielle Le mal dêtre femme. La femme et la medecine a Rome. París 1984. pp. 197 y ss. 
Se advierte también de la escasa eficacia de métodos mágicos para evitar la concepción, diciendo que no se usen amuletos como la araña envuelta en piel de ciervo o los fabricados con matrices de mulas ${ }^{9}$.

El que la ciencia haya demostrado y explicado el funcionamiento de muchas de estas plantas y recetas (de hecho casi todas las citadas, por ejemplo, por Sorano $)^{10}$ nos debe mostrar que no solo hay una voluntad de control demográfico sino que los conocimientos sobre ello son bastante avanzados y empíricos, por lo que para llegar a esa puesta por escrito se ha necesitado una experimentación y probablemente una transmisión oral muy anteriores. Es posible que algunas de las recetas más ineficaces puedan ser sustituciones, o modificaciones, buscando plantas más fáciles de conseguir en una zona donde no se dé la especie citada en una receta concreta. Así pues la anticoncepción y el aborto debieron ser bastante más corrientes de lo que se ha venido pensando hasta ahora.

Mientras que en la literatura médica se exponen las recetas sin tapujos, la legislación nos muestra penas muy duras para las mujeres que aborten, estableciendo castigos que van desde el destierro a la muerte, e incluso algunos resultan peores que la muerte, como encontramos en las leyes asirias, en las que nos podemos ver que la mujer condenada por aborto será empalada (y) no se la enterrará, quedando así maldita aún tras la muerte. En cambio si la mujer aborta por orden del marido no hay pena alguna ${ }^{11}$. Podría pensarse que es una pena por homicidio, pero encontramos que está penada con la muerte no solo el homicidio sino también delitos como la brujería, el robo de objetos al marido enfermo o la violación a la mujer casada ${ }^{12}$. Y tenemos que tener en cuenta que no solo conllevan una ejecución como en esos delitos, sino también una maldición más allá de la muerte , además del detalle de que la condena solo se aplica si es la mujer la que se practica el aborto.

En el Éxodo vemos cómo se pena con una multa que se haga abortar a una mujer a golpes, pero si la mujer muere, los implicados son condenados a muerte ${ }^{13}$, quedando así claro que no se considera el aborto como un

9 Blázquez, José Ma "Los anticonceptivos en la Antigüedad Clásica” en Alfaro Giner, Carmen y Tirado Pascual, Marta (eds.) Actas del segundo seminario de Estudios sobre la Mujer en la Antigüedad (1998). Valencia 2000. pp. 135 y ss.

10 Riddle, J. M. Contraception and Abortion form de Ancient World to the Renaissance, Cambridge 1992. pp. 51 y ss.

11 Ruiz Cabrero, L.A. "Mujer y fertilidad entre los semitas noroccidentales" en <http:// moreprod.blogspot.com/2007/09/mujer-y-fertilidad-entre-los-semitas.html> Web del Proyecto PB97-0273

12 Klíma, J. Sociedady cultura en la Antigua Mesopotamia. Akal, 2007. pág. 208.

13 Éxodo 21: 22-23 
homicidio, pero sí un daño grave a la propiedad familiar. Lo mismo pasa en las leyes asirias con este caso.

Así mismo podemos ver que se impone en muchas legislaciones la severa vigilancia de la mujer embarazada, sobre todo si se acaba de divorciar o el marido ha muerto, y así leemos en el Digesto $(25,4, \mathrm{I}, 10)$ que si después de la muerte del marido, una mujer se declara encinta deberá manifestarlo en el mes siguiente a la muerte, a quienes tienen derecho o a sus representantes para que si éstos lo desean envien mujeres que inspeccionen el vientre. [...]. Treinta días antes de la fecha en que calcule parir, la mujer lo dará a conocer a quien tenga derecho o a sus representantes para que éstos envien a los guardianes del vientre.

La frase de esta norma que hace referencia a "quienes tengan derecho" nos da la clave para comprender qué se está castigando realmente. El delito cometido no es el de homicidio ni mucho menos, ya que el feto es considerado como una víscera más de la madre, y ni siquiera el recién nacido es considerado realmente una persona (de hecho los romanos los entierran en los aleros de las casas, y no de la manera tradicional), sino que se está castigando un robo al marido o sus familiares. Podemos observarlo más claramente en el Digesto $(47,11,4)$, donde leemos que Septimio Severo, de consagrada memoria, juntamente con Antonino Caracala, dieron un rescripto diciendo que la que se provocó el aborto deliberadamente debe ser desterrada temporalmente por orden del gobernador, pues puede parecer indignante que haya defraudado impunemente en los hijos a su marido.

Podemos comprobar esta visión del aborto como un robo y no como un homicidio cuando vemos las penas que se imponen en Roma a quienes proporcionen pócimas abortivas, a las que se iguala con las "amatorias". Así en el Digesto $(48,19,38,5)$ dice que los que procuraran pócimas abortivas o amatorias aunque no lo hagan con mala intención, sin embargo, como es un pésimo precedente, son relegados, los de clase bumilde a una mina, y los de mejor condición a una isla, previa confiscación de la mitad de sus bienes; pero si, a consecuencia de ello, muriera una mujer o un hombre, sufren la última pena. Así pues, el problema es el peligro que suponen estas recetas para quienes las toman, pudiendo fácilmente morir envenenados. Resulta curioso que la pena se impone aunque se realice "sin mala intención", y cabe preguntarse si hace referencia solo a las amatorias o, según parece también, a las abortivas.

Pero, como temas referidos a la reproducción, el aborto, o incluso la anticoncepción, no son exclusivamente un tema familiar, ya que la maternidad no es considerada una mera decisión privada de una familia en concreto, sino que es un asunto de Estado. Y un asunto de máxima importancia, ya que cada hijo es un futuro ciudadano y un futuro soldado. Además de ello, y aunque el Estado pueda llevar a cabo una política pronatalista mediante privilegios a las familias con muchos hijos o sanciones a los solteros, entra en juego la misma concepción que se tiene de la mujer y de la ciudadanía.

Llegados a este punto se hace necesario un inciso para explicar la diferencia establecida entre sexo y género. La palabra sexo se refiere a 
lo puramente biológico de la diferencia sexual, pero nos plantea serios problemas a la hora de analizar cómo cada sociedad entiende esa diferencia. Por ello surgió hace ya unos años el término "género", que se refiere a toda la construcción social en torno al sexo. Ann Oakley lo define como algo psicológico y cultural, añadiendo que el sentido común sugiere que son meramente dos formas de ver la misma división y que alguien que pertenece a, por ejemplo, el sexo femenino automáticamente pertenecerá al correspondiente género (femenino). En realidad esto no siempre es así. Ser un hombre o una mujer, un niño o una niña, está tanto en función del vestido, del gesto, ocupación, red de relaciones sociales y personalidad, como del hecho de poseer unos determinados genitales ${ }^{14}$. El problema viene dado por la consideración de ese discurso como algo natural, lo que impide su cuestionamiento y hace que quien se salga del mismo sea considerado no solo un delincuente, sino alguien fuera de la misma naturaleza.

En Grecia y en Roma se considera únicamente un género dual, frente a sociedades donde se aceptan terceros géneros o variedades y flexibilidad dentro de los mismos, como pasa con los nadle en el caso de los navajos que no son considerados ni hombres ni mujeres y pueden casarse con personas del género que elijan ${ }^{15}$ o las vírgenes juradas albanas que son consideradas a todos los efectos como hombres con la condición de permanecer castas ${ }^{16}$. Estas categorías intergenéricas no tienen por qué estar bien consideradas, como sucede con los serrer entre los pokot de Kenia ${ }^{17}$, pero aunque esté mal visto pertenecer a dicho tercer género, el caso es que se reconoce su existencia. Dentro de este tercer género reconocido se abarcan desde casos de lo que hoy consideraríamos transexualidad, homosexualidad o casos de hermafroditismo, como en el caso de personas aquejadas del síndrome de Klinefelter.

En torno a la dualidad de género griega y romana se construye todo el discurso de cómo debe ser el hombre y la mujer, colocando a cada lado de la balanza todo el resto de dualidades y definiendo así a un hombre cálido y seco, agresivo, fuerte y racional, mientras que la mujer es fría y húmeda, pacífica (aunque vemos que más bien deben ser mantenidas pacíficas ante el riesgo del descontrol de su ira), débil y emotiva. Sobre todo, se pone un gran énfasis en la pasividad femenina frente a la actividad masculina, que civiliza y doma a la mujer-naturaleza, plagandose la mitología de ejemplo de mujeres cazadoras o guerreras que se oponen pero son finalmente vencidas por el hombre que las lleva al matrimonio.

Así, por su propia naturaleza, los ámbitos y la misma ciudadanía

14 Oakley, A. Sex, Gender and Society. Londres, 1972. pág. 158.

15 Martín Casares, A. Antropología del género: culturas, mitos y estereotipos sexuales. Madrid 2006, pp. 56 y ss.

16 Izquierdo, M J., El malestar en la desigualdad. Madrid, 1998. pp. 35 y ss.

17 Young, A. Women who become men: Albania sworn virgins. Oxford, 2000. 
se dividen también, creyéndose complementarios ambos géneros y sus condiciones. El hombre ocupa el espacio público, el de las decisiones, la política y la guerra, mientras que la mujer ocupa el epacio privado, el de la reproducción física y moral de la sociedad, a través de una maternidad legítima y entregada. Hay que tener en cuenta que, aunque la mujer ocupe el ámbito privado, no quiere decir que tenga poder de decisión sobre él, pues ya hemos visto que es el hombre quien finalmente decide y detenta el poder. Así podemos verlo en las palabras de Jenofonte cuando habla de cómo al ser creada la raza humana, a la mujer, al darle un cuerpo menos capaz para estas fatigas II la divinidad le encomendó, me parece a mí, las faenas de dentro. Y sabiendo que habia inculcado en la mujer y le había encargado la crianza de los niños recién nacidos, también le adjudicó en el reparto un mayor cariño ${ }^{18}$. Y aún mejor lo vemos en las palabras de San Juan Crisóstomo cuando dice que puesto que los asuntos privados componen la condición humana, tanto como los públicos, Dios los ha repartido: todo lo que está fuera lo ba confiado a los hombres, todo lo que está en la casa a las mujeres ${ }^{19}$. Así pues, tanto los hombres que se comportan como mujeres como las mujeres que se comportan como hombres son considerados especialmente repugnantes en general, y podemos ver el desprecio de Platón al comparar a los varones con mujeres diciendo que no permitiremos de aquellos por quienes decimos interesarnos y que aspiramos a que sean hombres de bien imiten, siendo varones, a mujeres jóvenes o viejas que insultan a sus maridos o desafian a los dioses engreídas en su felicidad, o bien caen en el infortunio y se entregan a llantos y lamentaciones. Y mucho menos les permitiremos que imiten a enfermas o enamoradas o parturientas ${ }^{20}$.

Así pues, la mujer que decide por su cuenta abortar no solo está cometiendo un robo contra su marido, sino que está faltando gravemente a sus deberes como ciudadana, a la vez que va contra su propia naturaleza, dejando así de ser propiamente una mujer. Es la decisión y no la muerte del nasciturus la que horroriza a los legisladores y teóricos de la ciudadanía, ya que es aceptada en ciertos casos. Podemos ver que dicha muerte del hijo, o incluso si está ya crecido o es un adulto, debe afrontarla la mujer con valentía si se produce en beneficio de la ciudad. No debe quejarse la madre cuando le quitan al hijo. Y así lo leemos en palabras de Plutarco sobre los sacrificios de niños en Cartago, a los que la madre asistía sin lagrimas ni gemidos; si lloraba se deshonraba, sin poder impedir por ello el sacrificio ${ }^{21}$ o las palabras puestas por Platón en boca de Sócrates quien le pregunta a su interlocutor $\dot{ } \mathrm{O}$ bien crees

18 Jenofonte, Económico 7 (23-25). Traducción de Juan Zaragoza en Recuerdos de Sócrates, Económico, Banquete, Apología de Sócrates. Madrid, 1993.

19 Citado en Pedregal Rodríguez, $\mathrm{M}^{\mathrm{o}} \mathrm{A}$. "Los cristianos ante la familia: renuncia o reafirmación” Arys: Antigüedad: religiones y sociedades, 1, 1998, pp. 259-278.

20 Platón. República 395 d-e. Traducción de José Manuel Pabón y Manuel FernándezGaliano en La República, Madrid 1988.

21 Plutarco. Sobre la superstición, 13. En <http://moreprod.blogspot.com/2007/09lostextos-clsicos.html $>$ Web del Proyecto PB97-0273. 
que a todo trance es preciso criar a tu bijo, y no exponerlo? ¿Sufrirás con paciencia que se le examine y no montarás en cólera si se te arranca, como lo haría una primeriza si le quitaran a su primer hijo?22. Quizás el ejemplo extremo lo encontremos en los casos en que la madre mata al hijo adulto, como se dice de Damatria la espartana que mata a uno de sus hijos por haber sido cobarde en combate ${ }^{23}$, o bien se interponen entre él y la patria arriesgando su vida y rechazándolo, como en la historia de Coriolano. Aún así, ésto se considera un recurso exepcional.

Y no solo un recurso excepcional, sino que debe quedar claro que el asesinato o rechazo a los hijos se da por el bien de la comunidad, ya que en el caso contrario vemos la caracterización de las "malas madres" que ponen su maternidad por delante del bien común, como Medea al apropiarse de sus hijos por interés propio ${ }^{24}$, o Clitemnestra, que además de poner a su hija por delante de los intereses del ejército y de su padre, asume el mando en la ciudad de una forma "varonil", encarnando todo lo que una mujer no debe ser. La muerte de la hija no merece venganza, en cambio el asesinato del marido sacrificador lleva aparejada la pena de muerte, que lleva a cabo Orestes, sin que luego pueda serle aplicado el castigo por ello.

Esta aparente contradicción entre las diferentes formas de enfocar lo que "debería ser" según las circunstancias del momento podemos verla también en otro tópico clásico, como es la reclusión femenina. Las matronas romanas actuarán en un ámbito público en multitud de ocasiones de crisis tomando decisiones aparentemente masculinas, ya sea como devotas o protagonizando protestas como en el caso de Hortensia con la Lex Oppia ${ }^{25}$.

Para entender el castigo al aborto tenemos que analizar también el caso contrario, el de la mujer que muere de parto, como acto último de cumplimiento del deber ciudadano y con la propia esencia del ser.

La comparación entre la parturienta y el soldado será una constante en la literatura griega y romana, y en obras como la Iliada encontraremos a Agamenón herido, cuyos dolores son tan agudos como los de una mujer de parto, que le debilitan lo suficiente como para tener que retirarse ${ }^{26}$. Pero al contrario encontramos la queja que pone Eurípides en boca de Medea,

22 Platón Teeteto 161E. Traducción por Serafín Vargas González, en Teeteto. Español. Madrid, 2003.

23 Plutarco, Moralia 240 F.

24 No solo mata a sus hijos, arrebatándoselos a Jasón, sino que se niega a entregar los cadaveres, reclamandolos como propios.

25 Cid López, R.M “Mujeres y actividades políticas en la República. Las matronas rebeldes y sus antecesoras en la Roma Antigua" en Almudena Domínguez Arranz (ed.) Mujeres en la Antigüedad Clásica. Madrid, 2010. pp. 125-151.

26 Iliada XI 264-238. 
diciendo que los hombres dicen que vivimos en casa una existencia segura mientras ellos con lanza combaten, más sin razón: tres veces formar con el escudo preferiría yo antes que parir una sola ${ }^{27}$. Así, aunque en la Orestíada se diga que no se puede comparar la muerte del héroe con la de la mujer, pues ésta nada vale, en general vemos esa tendencia que Nicole Loraux resume en sufrir como una mujer, morir como un hombre ${ }^{28}$.

Y no solo aparece en la literatura esta asimilación, ya que podemos encontrar huellas arqueológicas también, como pueden ser los relieves de las tumbas hallados en la necrópolis del cerámico en Atenas, en los que no se representa el momento de la muerte salvo en dos casos especiales, el del soldado muerto en batalla y el de la mujer muerta en el parto, que suele aparecer entregando al niño a la familia. Así mismo un epitafio de una de estas mujeres muestra el mismo vocabulario usado para los soldados, al modo de un kourios homérico ${ }^{29}$. Del mismo modo, en el entrenamiento de los jóvenes espartanos vemos cómo tanto hombres como mujeres son sometidos a un fuerte ejercicio físico, ellos para soportar la guerra, y ellas para poder parir nuevos y fuertes soldados para la polis.

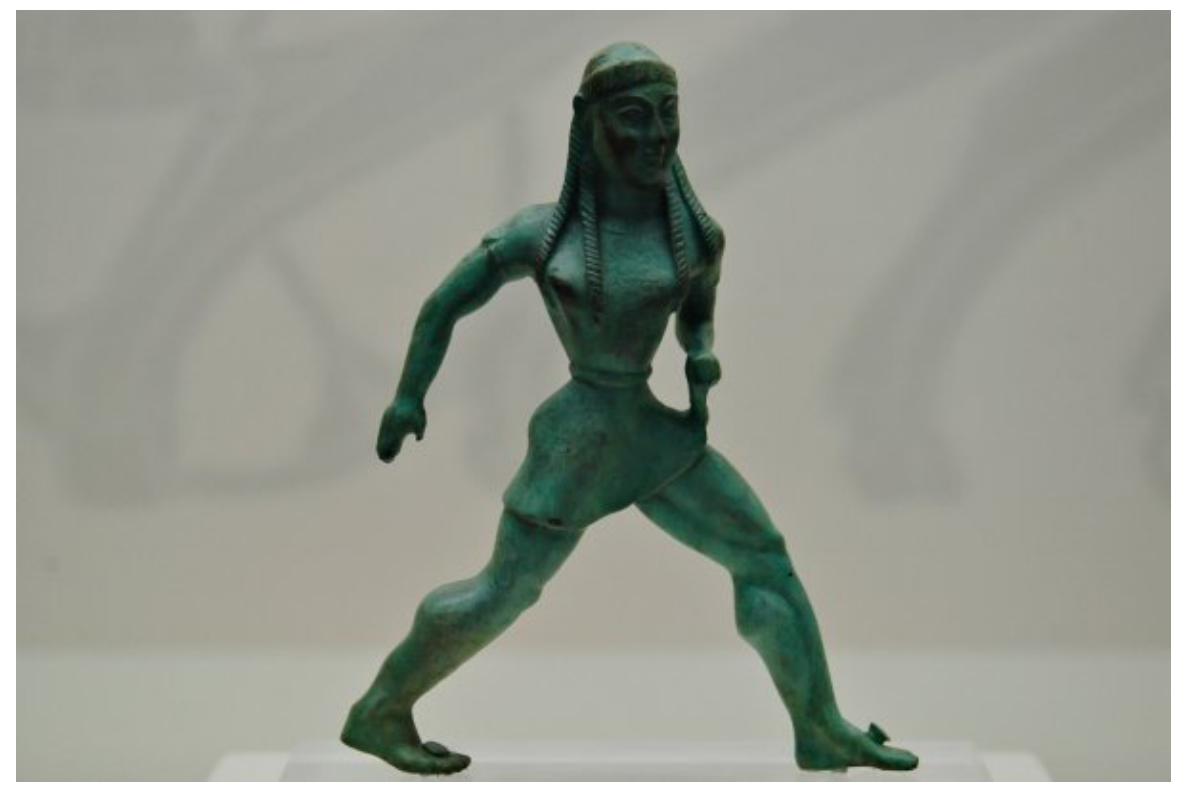

27 Eurípides, Medea 248-251. traducción por Francisco R. Adrados, en Tragedias. Vol. III. Medea. Madrid, 1995.

28 Loraux, N. Las experiencias de Tiresias (Lo masculino y lo femenino en el mundo griego). Barcelona, 2004. pp 81 y ss.

29 Loraux, N. Las experiencias de Tiresias (Lo masculino y lo femenino en el mundo griego). Barcelona, 2004. pp 46 y ss. 
Fig. I. Espartana en carrera. Olimpia

Hasta tal punto es importante la maternidad como articulación de la feminidad que, por ejemplo, la palabra que se opone realmente al ánthropos griego, es gyné, que se refiere a la esposa que ya ha sido madre. Así mismo la palabra latina matrona deriva directamente del término mater.

Así pues, es la alienación de la maternidad y del propio cuerpo de la ciudadana en el mundo antiguo la que lleva a que su iniciativa en el control de la misma sea considerada una grave ruptura del orden natural y de la ciudad, y hay que tener en cuenta que eso conlleva también una grave ruptura religiosa. Pero esa misma alienación, ese deber de producir nuevos ciudadanos legítimos, parecidos al padre y fieles cumplidores del orden social, además de conllevar una serie de estrictas obligaciones, lleva también aparejada una protección. Es decir, unos derechos y deberes para con la familia y la polis, una ciudadanía femenina, que si bien no es igual a la masculina, si es claramente identificable cuando la comparamos con la ausencia de ella en, por ejemplo, esclavas, extranjeras o, sobre todo, prostitutas.

Estas últimas, acreedoras de la infamia por su profesión, por mucho que puedan llegar a ser ricas, conocidas o influyentes, nunca van a poder aportar hijos legítimos a la polis. A menos que se hagan pasar por honradas "madres", pero eso puede traer graves consecuencias como podemos advertir en el litigio que queda reflejado en el discurso Contra Neera de Demóstenes. Como no van a poder tener hijos legítimos, se ven libres de muchas de las prohibiciones que restringen a las ciudadanas y a veces pueden llegar a masculinizarse en sus atribuciones. De hecho, su vestimenta en Roma, en contraposición de los atributos de las matronas, es una toga gris, asimilándose más a la vestimenta masculina que a la femenina y puede ejercer, en cierto modo, un rol activo, ahora bien, al carecer de fama puede ser forzada sexualmente y están jurídicamente incapacitadas ${ }^{30}$.

Del mismo modo, no tiene restringido el acceso al vino, restringido en general a las mujeres ciudadanas, no solo porque se asocie al descontrol y la impudicia, sino también probablemente por ser un potente abortivo. No se casan legítimamente, y no serán acusadas de adulterio, ni de aborto e incluso en los casos de mujeres acusadas en Roma de subvertir el órden público o de envenenamientos colectivos veremos siempre condenadas a las matronas.

Un buen ejemplo de la ceguera voluntaria hacia las posibles prácticas abortivas y anticonceptivas de las prostituas es la creencia en la infertilidad de todas ellas, que se mantiene a lo largo del tiempo y en la Edad Media seguimos encontrando referencias a la matriz encenagada de la prostituta

30 Manzano Chinchilla, G. "La "no mujer": categorización social de la prostituta libre en Roma" en Actas de la IX Edición del Encuentro de Jóvenes Investigadores de Historia Antigua. Universidad Complutense de Madrid. En prensa. 
que le impide concebir o a la necesidad del orgasmo para concebir y si bien es posible que las infecciones hicieran a muchas prostitutas realmente estériles, debemos suponer que también encubrían otras prácticas que no querían ser vistas ${ }^{31}$. Así mismo, encontramos crencias como la de que las posturas y movimientos voluptuosos de las prostitutas impiden la fecundación, frente a las castas posturas y la ausencia de movimiento de las legitimamente casadas $^{32}$. En la legislación sobre prostitución en Europa el problema del embarazo solo aparece muy tardíamente, mientras que las revisiones médicas aparecen mucho antes, pero relacionadas con las enfermedades venéreas, y con la prohibición de ejercer desde cierto periodo y no con la comprobación temprana de que pudiera estar embarazada, como puede verse en el Reglamento para el servicio de Higiene Especial de la ciudad de Jerez de la Frontera, redactado en 1876, en el que se prohibe ejercer a partir del séptimo mes $^{33}$.

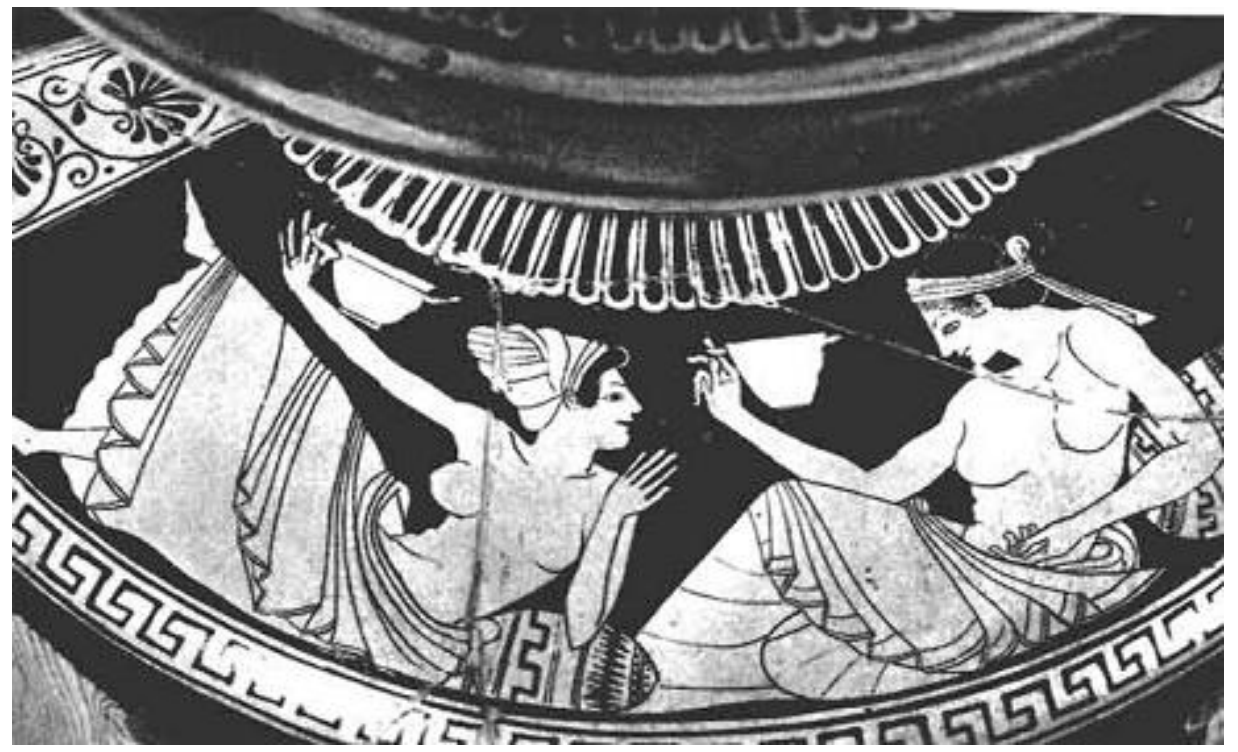

Fig. II. Heteras bebiendo.

Otra figura importante a la hora de comprender la visión de estas prácticas es la figura de la bruja o de la mujer caída. La imágen de la bruja,

31 Jacquart, D.; Thomasset, C. Sexualidad y saber médico en la Edad Media. Barcelona 1989. pp. 16 y ss.

32 Gourevitch, Danielle Le mal dêtre femme. La femme et la medecine a Rome. París 1984. pp. 197 y ss.

33 Vázquez, F. (coord). Mal Menor. Políticas y representaciones de la prostitución. Siglos XVI-XIX. Cádiz 1998. pp. 177 y ss. 
conocedora de las hierbas y sus propiedades, que se transmite es, o bien la belleza traidora y tentadora que lleva a la ruina (como Circe) o bien la fealdad más repugnante de la imágen que ha llegado a nosotros a través de la tradición. El temor a la mujer ducha en conocimientos de plantas, que pueden ser usadas tanto a modo de remedios como a modo de venenos, aflora comunmente en la tradición. El conocimiento transmitido oralmente por las mujeres puede verse reflejado en estos contramodelos míticos, inspirados y vistos seguramente en muchas mujeres reales. La figura de la mujer médico será asociada a la figura de la hechicera, ya se considera que una mujer que puede curar puede también llegar a emplear con perversidad su conocimiento llevada por la debilidad e irascibilidad de su sexo. Aunque encontramos testimonios de mujeres que ejercen la medicina tanto en la antigüedad, y son respetadas por ello, con lápidas como la de Iulia Saturnina en Mérida ${ }^{34}$ como en la Edad Media, donde aún en el siglo XIII existía en el francés el femenino de la palabra usada para el médico (mire/miresse), en épocas posteriores serán las comadronas y curanderas, las más afectadas por la caza de brujas institucional ${ }^{35}$, sobre todo si eran ya ancianas o vivían solas, convirtiéndose automáticamente en sospechosas si moría un recién nacido o si alguien enfermaba.

Podemos ver también ambos lados de esta moneda de la feminidad, con la imagen sobre la vergüenza o el orgullo en cuanto a la fecundidad en dos textos latinos. El primero muestra a las mujeres que acompañan a Prisciliano en sus viajes, diciendo que entre ellas estaban Eucrocia y su hija Prócula, sobre la cual corrieron rumores de que, embarazada de Prisciliano habia abortado ingiriendo hierbas ${ }^{36}$. Recurriendo al "chismorreo" para desacreditar a Prócula, se desacredita también con ello a todo su entorno y por tanto a Prisciliano, que no quiere o no puede imponer su autoridad. Por el contrario, una tierna exhortación a una mujer desolada la encontramos en la Consolación a Helvia, de Séneca, que se dirige a ella en estos términos: nunca te avergonzaste de tu fecundidad, como si te reprochara tu edad, nunca, a la manera de otras cuya reputación procede solo de su belleza, disimulaste tu vientre hinchado como si fuera una carga indecorosa ni destruiste en tus entrañas las esperanzas concebidas de hijos ${ }^{37}$.

La realidad es que el número de embarazos fue bajando conforme pasaba el tiempo y también en sociedades que intepretamos como más

\section{CIL II 497.}

35 García Aranguez, L. "Médicas y sanadoras en la sociedad medieval: Imágenes femeninas desde una perspectiva profesional" en Teresa Sauret Guerrero y Amparo Quiles Faz (eds.) Luchas de género en la Historia a través de la imágen. Tomo I. Málaga, 2002. pp.503-515.

36 Sulpicio Severo, Crónica II, 48, 3. En <http://www.thelatinlibrary.com/ sulpiciusseveruschron $2 . h t m l>$

37 Séneca, Consolación a Helvia XVI. Traducción por Juan Mainé Isidro en Diálogos. Consolaciones a Marcia, a su madre Helvia y a Polibio. Apolocintosis. Madrid, 1996. 
favorables a la mujer. Así, sabemos que los embarazos entre las espartanas eran mucho más tardíos que entre las atenienses, ya que se casaban sobre los veinte años y no recién púberes ${ }^{38}$. Así mismo en Roma tuvo que darse privilegios a las madres que tuvieran más hijos con el ius trius liberorum, que suponía, además de otras ventajas y el permiso para heredar, la liberación de la tutela masculina, cosa nada despreciable. Una legislación parecida la encontramos también en Esparta. Se impone además en ambas zonas medidas que penalizan la soltería.

Hay que destacar también los estudios realizados sobre esqueletos de mujeres de distintos momentos de la Antigüedad griega y romana por J. Lawrence Angel, quien, basándose en las pruebas que dejan los partos en los esqueletos femeninos (como por ejemplo lesiones en la pelvis), ha calculado que el número de embarazos por mujer fue bajando desde los 5 de las mujeres del 2.000 a.C. a los 4.1 en el 1.150 a.C., los 3.6 del 300 a.C. o los apenas 3.3 de la Roma imperial. Estos indicadores pueden no ser tan precisos como los autores de los estudios hacen ver, pero no dejan de ser significativos ${ }^{39}$

En conclusión, el aborto en la Antigüedad es un tema complejo, con distintas visiones del mismo, dependiendo del status, género y condiciones de quien lo practique, ya que no se condena la práctica en sí misma (ya que el control demográfico es un hecho en el mundo antiguo, realizado por los métodos más expeditivos si hace falta), sino la ruptura por parte de una ciudadana de lo que articula todo su ser y todos sus privilegios, que es la maternidad y la legitimidad que transmite con ella. Pero seguimos perdiendo, en el mar de informaciones que tenemos, la voz de las mujeres, que arriesgan su vida abortando clandestinamente para evitar las consecuencias sociales de un adulterio, que limitan su descendencia por su cuenta, que ayudan a otras mujeres a hacerlo o que transmiten la información que poseen de boca en boca.

38 Fornis, César. Esparta. Historia, sociedad y cultura de un mito historiográfico. Barcelona 2002. pp. 275 y ss.

39 Riddle, John M. Contraception and Abortion form de Ancient World to the Renaissance, Cambridge 1992. Pág. 15. 


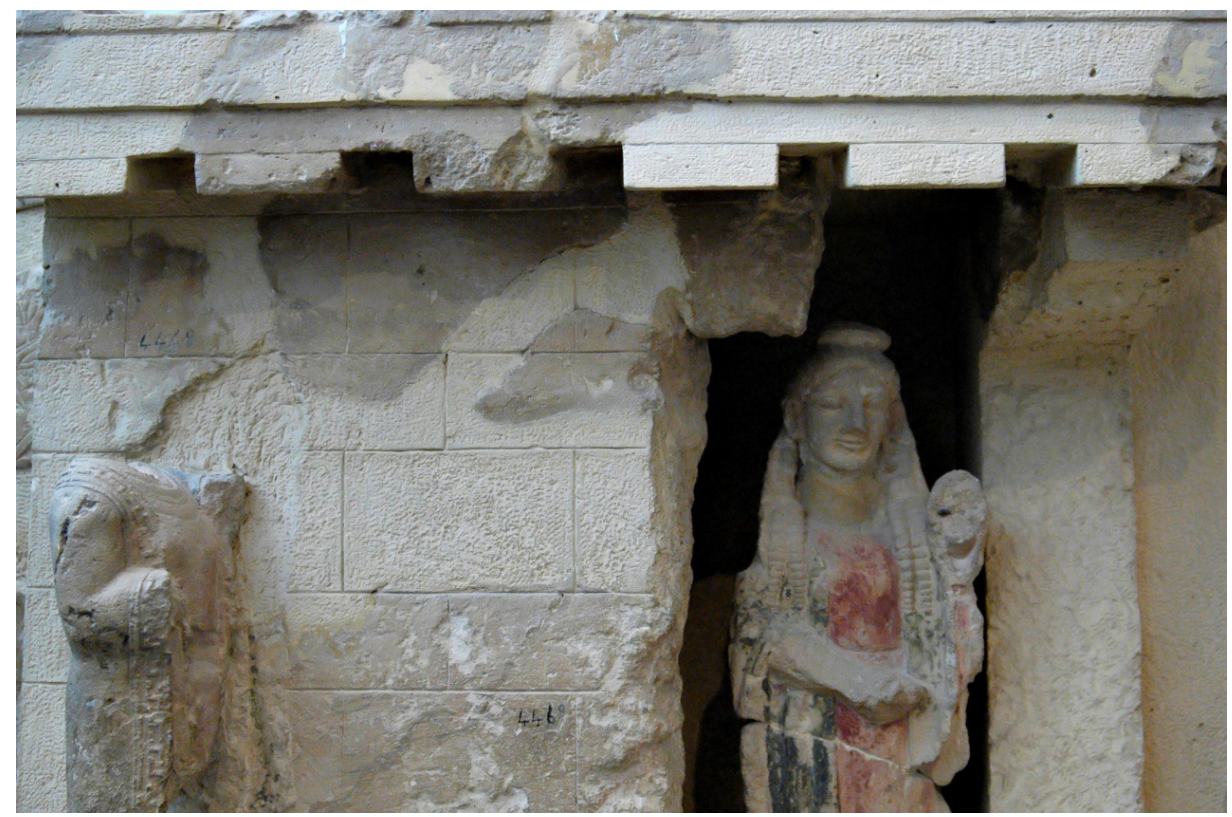

Fig. III. Mujer en casa. Museo de la Acrópolis.

Las fuentes, la epigrafía... nos muestran una realidad que "debería ser" y contruyen una dicotomía clásica entre espacio público y privado que es en gran parte una falacia. Lo es por la supuesta autoridad femenina en el ámbito privado, ya que se ve expuesta a la autoridad real masculina y de la comunidad en general hasta el punto de controlar su sexualidad y su maternidad. Lo es también por la imposible separación de espacios, ya que el espacio público se ve invadido por mujeres, ya sea por esclavas o prostitutas en los márgenes de la ciudadanía o por mujeres honradas y respetadas en ámbitos religiosos o evergéticos. Las continuas alusiones a la maternidad o su evitación por uno u otro método pueden ayudarnos a descubrir un aspecto más real de sociedades que tendemos a observar únicamente a través del cristal de la imagen que nos han querido dar teóricos y poderosos. Más allá del cristal que nos deja una visión masculina de la realidad. 